\title{
Does the ingestion of a 24 hour low glycaemic index Asian mixed meal diet improve glycaemic response and promote fat oxidation? A controlled, randomized cross-over study
}

\author{
Stefan Gerardus Camps ${ }^{1 *}$, Bhupinder Kaur ${ }^{1}$, Rina Yu Chin Quek ${ }^{1}$ and Christiani Jeyakumar Henry ${ }^{1,2}$
}

\begin{abstract}
Background: The health benefits of consuming a low glycaemic index ( $G l)$ diet to reduce the risk of type 2 Diabetes are well recognized. In recent years the Gl values of various foods have been determined. Their efficacy in constructing and consuming a low $\mathrm{Gl}$ diet over $24 \mathrm{~h}$ in modulating glycaemic response has not been fully documented. The translation of using single-point Gl values of foods to develop a $24 \mathrm{~h}$ mixed meal diet can provide valuable information to consumers, researchers and dietitians to optimize food choice for glycaemic control. By using Gl values of foods to develop mixed meals, our study is the first to determine how both blood glucose and substrate oxidation may be modulated over $24 \mathrm{~h}$.

Methods: The study included 11 Asian men with a BMI between $17-24 \mathrm{~kg} / \mathrm{m}^{2}$ who followed both a 1-day low Gl and 1-day high Gl diet in a randomized, controlled cross-over design. Test meals included breakfast, lunch, snack and dinner. Glycaemic response was measured continuously for over $24 \mathrm{~h}$ and postprandial substrate oxidation for $10 \mathrm{~h}$ inside a whole body calorimeter.

Results: The low Gl diet resulted in lower 24 h glucose iAUC ( $860 \pm 440$ vs $1329 \pm 614$ mmol/L.min; $p=0.014)$ with lower postprandial glucose iAUC after breakfast $(p<0.001)$, lunch $(p=0.009)$, snack $(p=0.012)$ and dinner $(p=0.003)$. Moreover, $24 \mathrm{~h}$ mean amplitude of glycaemic excursion was lower during the low $\mathrm{Gl}$ vs high $\mathrm{Gl}$ diet $(1.44 \pm 0.63$ vs $2.33 \pm 0.82 \mathrm{mmol} / \mathrm{L} ; p<0.001)$. Simultaneously, decrease in $10 \mathrm{~h}$ fat oxidation was less during the low vs high Gl diet $(-0.033 \pm 0.021$ vs $-0.050 \pm 0.017 \mathrm{~g} / \mathrm{min} ; \mathrm{p}<0.001)$, specifically after breakfast $(p<0.001)$ and lunch $(p<0.001)$.

Conclusions: Our study corroborates that using low Gl local foods to construct a $24 \mathrm{~h}$ low Gl diet, is able to reduce glycaemic response and variability as recorded by continuous glucose monitoring. Our observations also confirm that a low Gl diet promotes fat oxidation over carbohydrate oxidation when compared to a high GI diet. These observations provide public health support for the encouragement of healthier nutrition choices by consuming low Gl foods.
\end{abstract}

Trial registration: NCT 02631083 (Clinicaltrials.gov).

Keywords: Glycaemic index, Mixed meals, 24 h diet, Glycaemic response, Continuous glucose monitoring, Substrate oxidation, Indirect calorimetry, Whole body calorimeter

\footnotetext{
* Correspondence: Stefan_camps@sics.a-star.edu.sg

${ }^{1}$ Clinical Nutrition Research Centre (CNRC), Singapore Institute for Clinical

Sciences (SICS), Agency for Science, Technology and Research (A*STAR) and

National University Health System, Centre for Translational Medicine, Yong

Loo Lin School of Medicine, 14 Medical Drive \#07-02, MD 6 Building,

Singapore 117599, Singapore

Full list of author information is available at the end of the article
} 


\section{Background}

Glycaemic index (GI) of foods is a method of classifying foods based on postprandial glycaemic responses [1]. This response has been quantified and there is a large body of published GI values of food and food products available [2, 3]. Despite numerous papers extolling the health benefits of consuming a low GI foods to reduce the risk of type 2 Diabetes and metabolic syndrome [4], a major criticism of its utility has been that many studies have only reported the effects of feeding individual low GI foods, notably as incremental area under curve of blood glucose over a $2 \mathrm{~h}$ period. Little is known about the effect of feeding a low or high GI diet at breakfast, lunch, snack and dinner on $24 \mathrm{~h}$ glucose profiles in young healthy Asians. Findings from continuous glucose monitoring in Caucasians with Diabetes indicate that consumption of a low GI diet may reduce glucose excursions and improve glycaemic control [5-7]. It is imperative to investigate the $24 \mathrm{~h}$ glucose response to feeding low or high GI mixed meal diets over a $24 \mathrm{~h}$ period in the Asian population, if people are to be encouraged to follow a low GI diet over several days.

Although the concept of GI has been widely accepted in Canada, parts of Europe and Australia, it still remains a novelty in Asia. This is paradoxical as the impact and importance of consuming a low GI diet may be of greater significance in Asia since the Asian phenotype has been shown to be more susceptible to Diabetes compared to Caucasians $[8,9]$. Additionally, the Asian diets are predominantly based on a high carbohydrate, high GI foods including rice. Indeed, in certain regions of Asia, example Myanmar, over $70 \%$ of the calories consumed comes from the consumption of rice $[10,11]$. In contrast to several studies and reports of GI values of Western foods, it is only in recent years that the GI of various Asian foods has been determined [12-16].

With the lack of published GI values of local foods, Henry and colleagues among others conducted several studies which determined the GI values of local commonly consumed foods, that were not previously tested [13]. The GI values of local foods provide valuable information to consumers, researchers and dietitians to optimize food choice for glycaemic control. However, these GI values have been single food measurements conducted in an Asian population and need to be translated to mixed meals typically consumed in Singapore. Using GI values obtained from local foods, our study is the first to determine how $24 \mathrm{~h}$ blood glucose may be modulated in healthy Asians.

In addition to glycaemic health improvement, there is an increasing interest in the use of low GI foods in the management and prevention of obesity. Low GI foods have been hypothesized to benefit weight control by promoting satiety and fat oxidation at the expense of carbohydrate oxidation [17-19]. A recent published study by our group showed that consumption of low GI foods favoured an increase in fat oxidation in Asian subjects [20]. It is necessary to take traditional eating habits of the Asian population into account to allow a better selection of local foods with beneficial effects to minimize hyperglycaemia and increase fat oxidation.

Using continuous glucose monitoring and indirect calorimetry, our goal was to determine simultaneously, the glycaemic response and effect on substrate oxidation of a low GI mixed meal sequence developed with local Asian foods. The novelty of this study was that instead of single food GI studies, we investigated in an acute design, if consuming mixed meals based on local foods that are low in GI can reduce glycaemia over $24 \mathrm{~h}$ and increase fat oxidation. As the mixed meals were based on foods typically consumed in South-East Asia, this information can be relevant not only to plan diabetes diets but also to reduce the risk of developing type 2 Diabetes and obesity in this region. This study was designed to use commonly consumed foods sold mostly in coffee shops and hawker centres in Singapore that represent the type of foods commonly consumed all over Asia.

\section{Methods}

This randomized control trial was conducted at the Clinical Nutrition Research Centre (CNRC) within the Singapore Institute of Clinical Sciences (SICS), Agency of Science Technology and Research (A*STAR), Singapore. The study received ethical approval from the Domain Specific Review Board of the National Healthcare Group in Singapore (NHG DSRB Reference No. 2014/00960). Written informed consent was obtained from all eligible participants before commencement and the research procedures and trial protocols were followed in accordance to good clinical practice (GCP) guidelines and with the ethical standards in concordance to the Declaration of Helsinki, 1983. This trial was registered within clinicaltrials.gov under trial registration no. NCT 02631083.

Eleven healthy Chinese adults were recruited using a variety of methods which included flyers, online advertisements and personal communication. Subjects underwent an initial screening and measurements included anthropometry (height, weight, waist and hip circumference), fat percentage via air displacement plethysmography (BodPod, Life Measurements Inc, Concord, CA, USA), blood pressure, resting heart rate, fasting blood glucose and \% $\mathrm{HbA} 1 \mathrm{C}$. Physical activity was quantified using the questionnaire by Baecke et al. [21]. Eating behaviour was quantified using a Dutch eating behaviour questionnaire by Van Strien et al. [22]. Eleven subjects fulfilled the following inclusion criteria: male, age: $21-40$ years; body mass index 17$25 \mathrm{~kg} / \mathrm{m}^{2}$; no metabolic diseases; not on prescription medication; not allergic/intolerant to any of the test 
foods; not intentionally restricting food intake; fasting blood glucose $<6 \mathrm{mmol} / \mathrm{L}$. Baseline anthropometric and biochemistry data of the study participants are shown in Table 1.

\section{Study design}

The study had a randomized, controlled cross-over design with subjects attending two test sessions separated by a wash-out period of at least five days. The two test session included either a low glycaemic index (LGI) or a high glycaemic index (HGI) meal sequence (breakfast, lunch, snack and dinner). Participants were advised not to perform any rigorous activities three days prior to the study and during the study session. Each test session spanned over three consecutive days from 17:00 on Day 1 till 9:00 on Day 3 consisting of over $42 \mathrm{~h}$ continuous glucose monitoring (CGM) and a $10 \mathrm{~h}$ measurement of energy expenditure and substrate oxidation in a whole body calorimeter (WBC). During Day 2, participants stayed in the WBC room from 08:00 to 18:00 (10 h). For the first $45 \mathrm{~min}$, they were asked to lie in a supine position on the bed to measure their basal metabolic rate (BMR). Participants were then given the LGI or HGI test breakfast, lunch and snack to consume. After the stay in the WBC, a LGI or HGI dinner was provided. Participants were free to study, surf the net, watch television, listen to radio, use the telephone or lie on the bed however, they were not allowed to sleep during their time in the WBC. They were also encouraged to keep to one activity after consuming the meal and to minimize movement. A schematic study flow is presented in Fig. 1. Online computer software was used for simple randomization of the sequence of the treatment diets (www.randomizer.org).

\section{Test meals}

A standardized dinner was provided on Day 1 consisting of a ready-to-eat meal of teriyaki chicken with rice, one

Table 1 Baseline measurements of study participants $(n=11)$

\begin{tabular}{lr}
\hline Characteristic & Mean $\pm \mathrm{SD}$ \\
\hline Age (years) & $24.5 \pm 2.0$ \\
Height $(\mathrm{m})$ & $1.75 \pm 0.1$ \\
Weight $(\mathrm{kg})$ & $67.0 \pm 4.7$ \\
BMI $\left(\mathrm{kg} / \mathrm{m}^{2}\right)$ & $21.9 \pm 1.4$ \\
Waist circumference $(\mathrm{cm})$ & $74.7 \pm 4.5$ \\
Fasting blood glucose $(\mathrm{mmol} / \mathrm{L})$ & $4.6 \pm 0.4$ \\
HbA1c $(\%)$ & $5.1 \pm 0.2$ \\
Body fat $(\%)$ & $16.0 \pm 2.8$ \\
Basal metabolic rate & $1456 \pm 97$ \\
Systolic blood pressure $(\mathrm{mmHg})$ & $115.7 \pm 9.7$ \\
Diastolic blood pressure $(\mathrm{mmHg})$ & $69.5 \pm 9.2$ \\
\hline
\end{tabular}

drink and one jelly (energy: 879 kcal; Protein: 44.3 g; Fat: 18.3 g; Carbohydrate: 132.7 g).

Locally consumed foods were selected to construct the high and low GI test meals:

Low GI breakfast: Milo (Nestle, Singapore) GI: 36, low fat milk (Paul's, Australia) GI: 37, lemon puff biscuits (Khong Guan, Singapore) GI:49; High GI breakfast: pink rice cake (steamed sticky rice cake with dried pork radish filling; also called poon kueh) GI:97 (purchased from a local hawker stall, Singapore), rice cracker (Bin-Bin, Singapore) GI:83, Nestum cereal drink made with water (Nestle, Malaysia) GI: 77.

Low GI lunch: bee hoon (thin rice vermicelli) (Fairprice, Singapore) GI: 33, teriyaki chicken (Charoen Pokphand Intertrade, Singapore), fresh spinach GI:15; High GI lunch: mee pok (flat, yellow egg noodle varying in thickness and width) (Fortune, Singapore) GI: 73, fresh carrots GI: 49, teriyaki chicken (Charoen Pokphand Intertrade, Singapore), rice cracker (Bin-Bin, Singapore) GI:83. Both noodles for LGI and HGI were flavoured with some ketchup, sesame oil, dark soy sauce, water.

Low GI snack: kaya butter toast (toasted bread with butter and coconut jam made from coconut milk, eggs and sugar) (purchased from a local hawker stall, Singapore) GI:49, Milo (Nestle, Singapore) GI: 36, low fat milk (Paul's, Australia) GI: 37; High GI snack: steamed glutinous rice with chicken (steamed sticky rice with chicken and mushroom, also called lo mai gai) (purchased from a local hawker stall, Singapore) GI: 106, canned ice lemon tea (Fraser and Neave, Malaysia) GI: 74

Low GI dinner: parboiled basmati rice (Diabetic Specialities Pte Ltd, Singapore) GI: 55, chicken stock (Knorr chicken stock, Malaysia), fresh spinach, teriyaki chicken (Charoen Pokphand Intertrade, Singapore); High GI dinner: glutinous rice (sticky rice, it has a low amylose content and is especially sticky when cooked) (New Moon, Tek Seng Rice Mill Co. Ltd, Thailand) GI:92, chicken stock (Knorr chicken stock, Malaysia), fresh carrots GI: 49, margarine spread (Flora, Unilever, Australia), teriyaki chicken (Charoen Pokphand Intertrade, Singapore), rice cracker (Bin-Bin, Singapore) GI:83. The energy values and macronutrient composition of the test meals are provided in Tables 2 and 3 . The daily meals provided to the subjects matched their daily energy requirements based on the measured basal metabolic rate of a subject multiplied by a physical activity level of 1.5 .

The low and high GI meals were designed to obtain as wide a difference in the calculated meal GI values. The GI of individual foods were obtained using GI values 


\begin{tabular}{|c|c|c|}
\hline & Continuous glucose monitoring day 1 - day 3 ( \pm 40 hours) & \\
\hline $\begin{array}{l}\text { Day 1: 17:00 } \\
\cdot \quad \text { insertion CGMS } \\
\cdot \text { take home standard dinner }\end{array}$ & $\begin{array}{l}\text { Day 2: } 08.00-18.00 \\
\text { 10h WBC stay (indirect calorimetry) } \\
\text { - LGI or HGI test breakfast, lunch and snack } \\
\text { in WBC, followed by test dinner }\end{array}$ & $\begin{array}{l}\text { Day } 3 \text { 9:00 } \\
\cdot \quad \text { removal CGMS }\end{array}$ \\
\hline
\end{tabular}

Fig. 1 Study protocol. On day 1, the continuous glucose monitoring system (CGMS) was inserted in the afternoon. Subjects consumed a standardized dinner followed by an overnight fast. On day 2, subjects entered the whole body calorimeter (WBC) in a fasted state at 08:00, where basal metabolic rate (BMR) was measured for 45 min. Breakfast, lunch and snack low glycaemic index (LGI) or high glycaemic index (HGI) test meals were provided in the calorimeter. Subjects remained sedentary during the $10 \mathrm{~h}$ in the calorimeter. Subjects were allowed to leave the calorimeter at 18:00, after which the test dinner was provided. The CGMS was removed on day 3

from recognized tables [23] and from manufacturers' information. The meal GI was calculated using the mixed meal formula [24]. Subjects were requested to consume both breakfast and snack within $15 \mathrm{~min}$ and lunch within $20 \mathrm{~min}$.

\section{Interstitial glucose measurement}

Continuous glucose monitoring (CGM) (iPro ${ }^{\mathrm{Tw}} 2$ Professional CGM-Medtronic MiniMed, Northbridge, CA, USA) was used to measure glycaemic response, defined as the primary outcome. The insertion was performed on Day 1 at 17:00 and the sensor was removed on Day 3 of the study at 9:00. Data was collated and processed using online software (Medtronic Diabetes CareLink iPro; carelink.minimed.eu). The data reported in this paper represent $24 \mathrm{~h}$ interstitial glucose readings recorded every 5 min from 6:00 on Day 2 to 6:00 on Day 3. During each test session, the CGM sensor was calibrated against finger-stick blood glucose measurements four times a day before every meal and before sleeping using the OneTouch ${ }^{\circ} \mathrm{Ultra}^{\circ} 2$ blood glucose meter (LifeScan, Inc., Milpitas, CA, USA). A cross-over design with a minimum of 8 subjects would be sufficient to detect a $15 \%$ change in area under the glucose curve $(24 \mathrm{~h})$ with a power of 0.85 at a significance level of 0.05 as adapted from Brynes et al. $[25,26]$.

\section{Energy expenditure and substrate oxidation}

Basal metabolic rate (BMR), respiratory quotient (RQ) and substrate oxidation were measured for $10 \mathrm{~h}$ using a dual

Table 2 Macronutrient composition and Gl values of the test diets provided in the study

\begin{tabular}{lll}
\hline & Low Gl diet & High Gl diet \\
\hline Energy \% Carbohydrate & 62 & 64 \\
Energy \% Fat & 23 & 23 \\
Energy \% Protein & 14 & 12 \\
Meal Gl breakfast & 43 & 90 \\
Meal Gl lunch & 32 & 73 \\
Meal Gl snack & 43 & 95 \\
Meal Gl dinner & 53 & 85 \\
\hline
\end{tabular}

Gl: glycaemic index room WBC facility based on the system described by Schoffelen et al. [27]. Each WBC room is an open circuit, airtight indirect calorimeter with a total volume of $13.5 \mathrm{~m}^{3}$, furnished with a single-bed, a foldable chair, a bureau with built-in sink, deep-freeze toilet (Special Product, Mulders), a color television, an alarm clock, a radio, a telephone, a laptop, WIFI connection and an automated intercom for communication between the researcher and the participant. It is built to mimic a normal room with two windows for visual contact between the researcher and participant.

During test sessions, gaseous exchanges were measured continuously as oxygen consumption and carbon dioxide production through differences between inlet and outlet oxygen $\left(\mathrm{O}_{2}\right)$ and carbon dioxide $\left(\mathrm{CO}_{2}\right)$ concentrations. Oxygen concentration was measured using a paramagnetic $\mathrm{O}_{2}$ analyser (Model AO2020, module Magnos206, ABB Automation GmbH, Germany) while carbon dioxide concentration was measured using an infrared photometer (Model AO2020, module Uras26, ABB Automation $\mathrm{GmbH}$, Germany). The air samples are measured in an automated sequence and alternated with calibration span gas $\left(18 \% \mathrm{O}_{2}, 0.8 \% \mathrm{CO}_{2}\right.$, and balance nitrogen) and zero (100\% nitrogen) gases [27]. Gaseous exchanges were measured under standard temperature, pressure, and dry (STPD). The accuracy of the WBC chambers was routinely tested through the combustion of a known amount of methanol. The accuracy of $\mathrm{O}_{2}$ and $\mathrm{CO}_{2}$ measurements in our WBC facility were: $\mathrm{O}_{2}=$ $100.6 \pm 0.5 \%$ (chamber 1) and $100.9 \pm 0.4 \%$ (chamber 2), and $\mathrm{CO}_{2}=99.2 \pm 0.5 \%$ (chamber 1) and $99.7 \pm 0.5 \%$ (chamber 2), while the coefficient of variation was $3.0 \%$ $(n=21)$ for repeated 30-min RMR measurements with our WBC facility.

BMR was calculated based on volume of $\mathrm{O}_{2}$ consumption $\left(\mathrm{VO}_{2}\right)$ and $\mathrm{CO}_{2}$ production $\left(\mathrm{VCO}_{2}\right)$ using the Weir equation [28]. Postprandial substrate oxidation and respiratory quotient (RQ) were calculated from urinary nitrogen excretion, oxygen consumption and carbon dioxide production [29]. Urine samples were collected in the WBC over $10 \mathrm{~h}$ in a 3 litre urine collection container (Unisafe ${ }^{\oplus}$, Canada). The total volume of urine over $10 \mathrm{~h}$ was measured and a 
Table 3 Foods used to construct the test meals provided in the study

\begin{tabular}{|c|c|}
\hline Low Gl diet & High Gl diet \\
\hline Breakfast & Breakfast \\
\hline Milo, milk (low fat) lemon puff biscuits & $\begin{array}{l}\text { poon kueh (pink rice cake), rice cracker Nestum cereal } \\
\text { drink (made with water) }\end{array}$ \\
\hline Lunch & Lunch \\
\hline $\begin{array}{l}\text { bee hoon (rice vermicelli), sauce (ketchup, sesame oil, } \\
\text { dark soy, water), teriyaki chicken, spinach (boiled) }\end{array}$ & $\begin{array}{l}\text { mee pok (flat egg noodle), sauce (ketchup, sesame oil, } \\
\text { dark soy, water), teriyaki chicken, carrots (boiled), } \\
\text { rice cracker }\end{array}$ \\
\hline Snack & Snack \\
\hline $\begin{array}{l}\text { kaya butter toast (kaya is made from coconut milk, } \\
\text { eggs and sugar), } \\
\text { Milo, milk (low fat) }\end{array}$ & $\begin{array}{l}\text { steamed glutinous rice with chicken (lo mai gai), } \\
\text { ice lemon tea }\end{array}$ \\
\hline Dinner & Dinner \\
\hline $\begin{array}{l}\text { parboiled basmati rice, chicken stock, teriyaki chicken, } \\
\text { spinach (boiled) }\end{array}$ & $\begin{array}{l}\text { glutinous rice, chicken stock teriyaki chicken, carrots } \\
\text { (boiled then mixed with margarine), rice cracker }\end{array}$ \\
\hline
\end{tabular}

Gl, glycaemic index

homogenized urine sample was stored for nitrogen analysis. Nitrogen content (\%) was measured using the copper catalyst Kjeldahl method (AOAC Official Method 984.13). Protein oxidation $(\mathrm{g} / \mathrm{min})$ was calculated by multiplying $10 \mathrm{~h}$ urinary nitrogen $(\mathrm{g})$ by 6.25 and converted to per minute values. $\mathrm{CHO}$ oxidation and fat oxidation were calculated by using the following equations based on the volumes of $\mathrm{O}_{2}$ consumed and $\mathrm{CO}_{2}$ produced in oxidation of glucose, fat and protein as published by Frayn [30]: $\mathrm{CHO}$ oxidation $(\mathrm{g} / \mathrm{min})=-3.21 \times \mathrm{O}_{2}(\mathrm{l} / \mathrm{min})+4.55 \times \mathrm{CO}_{2}(\mathrm{l} / \mathrm{min})-$ $2.87 \times \mathrm{N}(\mathrm{g} / \mathrm{min})$ and fat oxidation $(\mathrm{g} / \mathrm{min})=1.67 \times \mathrm{O}_{2}$ $(1 / \mathrm{min})-1.67 \times \mathrm{CO}_{2}(\mathrm{l} / \mathrm{min})-1.92 \times \mathrm{N}(\mathrm{g} / \mathrm{min})$.

\section{Statistical analysis}

All statistical analyses were performed using Statistical Package for the Social Sciences version 23 (SPSS Inc.). Data and figures were processed in a Microsoft Excel spreadsheet (Microsoft Corporation). Values were presented as mean \pm SD unless otherwise stated. Prior to statistical analysis, the normality of the data was assured using the Shapiro-Wilks test.

The primary outcome of this study was to determine how a $24 \mathrm{~h}$ meal sequence including LGI and HGI local foods impacts on $24 \mathrm{~h}$ glycaemic response and variability and substrate oxidation.

First, the baseline glucose value for each subject was determined from the $1 \mathrm{~h}$ average CGM interstitial glucose readings in a fasted state from $6: 00$ to 7:00 on day 2 and used to calculate the change in glucose level for all $40 \mathrm{~h}$. Glycaemic response was expressed as the incremental area under the curve (iAUC) and calculated using the trapezoidal rule and the change in glucose above baseline [31, 32]. The GR values were important for further analyses such as the GR iAUC calculations, CGMS glucose curve construction and statistics.
Second, mean amplitude of glycaemic excursion (MAGE) was assessed as an indicator for glycaemic variability during the day [33-35]. MAGE was calculated using EasyGV software (available free at www.easygv.co.uk), with this software being extensively reviewed [36].

Third, baseline substrate oxidation and RQ were calculated from 45 min steady-state measurement of BMR in a fasted state and used to assess $10 \mathrm{~h}$ and postprandial changes from baseline. Additionally, substrate oxidation was also expressed as the grams of carbohydrates, fat and protein oxidised. Glycaemic parameters are based on all 11 subjects with complete CGM data sets for both the LGI and HGI diets. Substrate oxidation and RQ results are based on 9 subjects with a complete set of whole body calorimeter and urine nitrogen data for both the LGI and HGI diets. During two test sessions, two subjects failed to produce an adequate and representative amount of urine for nitrogen analysis and these were excluded from the analysis for substrate oxidation. Paired $\mathrm{t}$-test was performed to test the differences in the glycaemic response (one-tailed), MAGE and substrate oxidation (two-tailed) between LGI and HGI treatments diets and alpha $(\alpha)$ was set at 0.05 for statistical analyses.

\section{Results}

The baseline characteristics of the subjects are given in Table 1 . The anthropometric data were within normal ranges for this population.

\section{Continuous glucose monitoring interstitial glucose data}

The glycaemic profiles for the LGI and HGI diets are graphically presented in Fig. 2. The glycaemic outcome parameters, iAUC and MAGE, are presented in Table 4. Generally, the HGI intervention produced a sustained higher glycaemic response throughout the day (Fig. 2). During the LGI intervention, the iAUC following all 


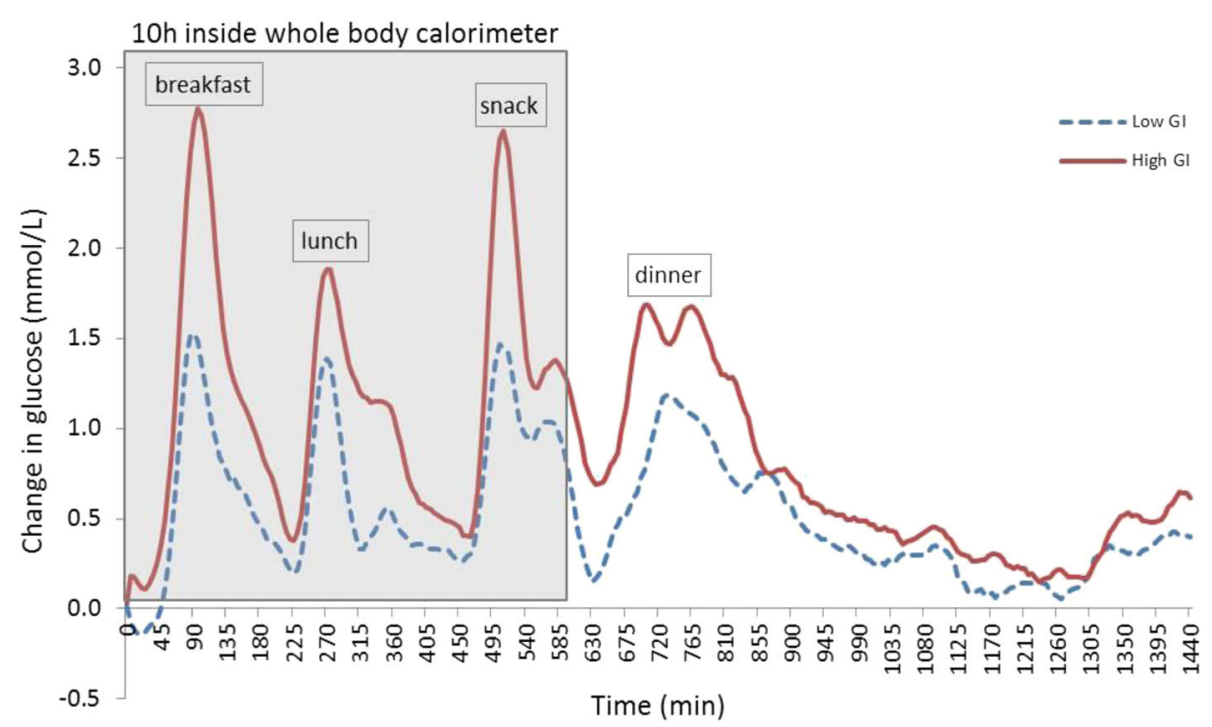

Fig. $24 \mathrm{~h}$ average change in interstitial glucose concentrations from baseline from subjects on a low Gl or high Gl diet $(n=11)$. CGM, continuous glucose monitoring (Overnight fast range from $960 \mathrm{~min}$ to $1440 \mathrm{~min}$ )

meals (i.e. breakfast, lunch, snack and dinner) were significantly lower $(P<0.05)$ compared to the HGI intervention. Overnight iAUC following the test dinner was not significantly different after the LGI diet $(P=0.140)$. Over $24 \mathrm{~h}$, there was a trend for a significantly lower iAUC during the LGI intervention $(P=0.056)$. During the $10 \mathrm{~h}$ in the WBC, there was a significantly lower GR during the LGI treatment compared to HGI $(P=0.012)$. Total daily AUC, which uses the absolute glucose values, was not significantly different between both treatments $(P=0.478)$. Glycaemic variability over the $24 \mathrm{~h}$ period, as assessed by MAGE showed a significantly lower variability during the LGI treatment $(P=0.003)$.

During the $10 \mathrm{~h}$ in the calorimeter, absolute RQ was lower during the LGI diet $(p=0.018)$ and RQ increased more during the HGI diet $(P<0.001)$. The greater increase in RQ during the HGI diet was seen specifically after breakfast and lunch $(p<0.001)$ but not after the snack. Correspondingly, carbohydrate oxidation was lower during the LGI diet over the $10 \mathrm{~h}$ in the whole body calorimeter $(p=0.011)$ and increased more during the HGI diet measured over $10 \mathrm{~h}(p<0.001)$, after breakfast $(p<0.001)$ and after lunch $(p=0.002)$ but not after the snack. $10 \mathrm{~h}$ fat oxidation was higher greater during the LGI diet $(p=0.002)$ and decreased less over $10 \mathrm{~h}(p<0.001)$ and postprandially after breakfast $(p<0.001)$, lunch $(p<0.001)$ during the LGI diet compared to the HGI diet; there was a trend for a smaller decrease in fat oxidation after the LGI snack $(p=0.076)$ (Table 5).

Table 6 shows the grams of oxidized macronutrients for $10 \mathrm{~h}$ on a LGI and HGI diet and separately for breakfast (until lunch), lunch (until snack) and the snack (until end). During the LGI diet, significantly less carbohydrate $(107.5 \mathrm{~g}$ vs $117.3 \mathrm{~g}, p=0.002)$ and more fat $(22.6$ vs $17.3, p=0.004$ ) were oxidized compared to the HGI diet. Greater fat oxidation was observed during the low GI diet after breakfast $(p=0.042)$ and lunch $(p<0.001)$

Table 4 Glycaemic outcome parameters for subjects on a low Gl and high Gl diet $(n=11)$

\begin{tabular}{llcl}
\hline Outcome measure & Low Gl & High Gl & $p$-value \\
\hline 24 h iAUC (mmol/L.min) & $859.8 \pm 439.7$ & $1329.4 \pm 613.6$ & 0.014 \\
iAUC in calorimeter (mmol/L.min) (10 h) & $423.9 \pm 234.3$ & $706.0 \pm 268.5$ & 0.002 \\
Breakfast iAUC (mmol/L.min) & $115.4 \pm 63.6$ & $209.7 \pm 62.6$ & $<0.001$ \\
Lunch iAUC (mmol/L.min) & $97.3 \pm 61.0$ & $162.1 \pm 75.0$ & 0.009 \\
Snack iAUC (mmol/L.min) & $129.2 \pm 67.8$ & $198.8 \pm 84.4$ & 0.012 \\
Dinner iAUC (mmol/L.min) & $122.7 \pm 79.9$ & $196.1 \pm 127.6$ & 0.003 \\
Overnight iAUC (mmol/L.min) (after test dinner) & $201.2 \pm 148.9$ & $259.0 \pm 202.1$ & 0.232 \\
MAGE over 24 h (mmol/L) & $1.44 \pm 0.63$ & $2.33 \pm 0.82$ & $<0.001$ \\
\hline
\end{tabular}

Values are expressed as mean \pm SD; Gl: glycaemic index; MAGE: mean amplitude of glycaemic excursion

$P$-values from paired students $t$-test when comparing glycaemic parameters between the low and high $\mathrm{Gl}$ diet 
Table 5 Substrate oxidation parameters for subjects on a low Gl and high Gl diet $(n=9)$, with incremental changes from pre-breakfast baseline

\begin{tabular}{|c|c|c|c|}
\hline Outcome measure & Low Gl & High Gl & $p$-value \\
\hline$\overline{R Q}(10 \mathrm{~h})$ & $0.887 \pm 0.038$ & $0.898 \pm 0.032$ & 0.018 \\
\hline Incremental RQ (10 h) & $0.074 \pm 0.038$ & $0.099 \pm 0.032$ & $<0.001$ \\
\hline Incremental RQ breakfast & $0.064 \pm 0.034$ & $0.087 \pm 0.026$ & $<0.001$ \\
\hline Incremental RQ lunch & $0.071 \pm 0.025$ & $0.103 \pm 0.026$ & $<0.001$ \\
\hline Incremental RQ snack & $0.102 \pm 0.046$ & $0.115 \pm 0.031$ & 0.287 \\
\hline CHO oxidation (10 h) (g/min) & $0.213 \pm 0.044$ & $0.229 \pm 0.042$ & 0.011 \\
\hline Incremental $\mathrm{CHO}$ oxidation (10 h) (g/min) & $0.105 \pm 0.044$ & $0.132 \pm 0.042$ & $<0.001$ \\
\hline Incremental CHO oxidation post-breakfast (g/min) & $0.085 \pm 0.039$ & $0.106 \pm 0.035$ & 0.002 \\
\hline Incremental $\mathrm{CHO}$ oxidation post-lunch (g/min) & $0.105 \pm 0.026$ & $0.140 \pm 0.037$ & $<0.001$ \\
\hline Incremental CHO oxidation post-snack (g/min) & $0.145 \pm 0.051$ & $0.161 \pm 0.043$ & 0.241 \\
\hline Fat oxidation (10 h) (g/min) & $0.043 \pm 0.021$ & $0.034 \pm 0.017$ & 0.002 \\
\hline Incremental fat oxidation (10 h) (g/min) & $-0.033 \pm 0.021$ & $-0.050 \pm 0.017$ & $<0.001$ \\
\hline Incremental fat oxidation post-breakfast (g/min) & $-0.032 \pm 0.017$ & $-0.047 \pm 0.023$ & $<0.001$ \\
\hline Incremental fat oxidation post-lunch (g/min) & $-0.033 \pm 0.014$ & $-0.052 \pm 0.015$ & $<0.001$ \\
\hline Incremental fat oxidation post-snack (g/min) & $-0.048 \pm 0.025$ & $-0.059 \pm 0.018$ & 0.076 \\
\hline
\end{tabular}

Values are expressed as mean $\pm \mathrm{SD} ; G l$ : glycaemic index; $R Q=$ respiratory quotient, $C H O=$ carbohydrate

$P$-values from paired students $t$-test when comparing substrate oxidation between the low and high $\mathrm{Gl}$ diet

with a similar trend after the snack $(p=0.079)$. There was no difference in protein oxidation between a LGI and HGI diet. There was no difference in energy expenditure over $10 \mathrm{~h}$ in the whole body calorimeter between the two dietary conditions (LGI $=749 \mathrm{kcal}$ and $\mathrm{HGI}=760 \mathrm{kcal}$ ), while there was a significant correlation between energy expenditure during LGI and HGI $\left(\mathrm{R}^{2}=0.82, p<0.001\right)$.

\section{Discussion}

The present study investigated the acute $24 \mathrm{~h}$ effects of the consumption of low GI mixed meals on simultaneously the blood glucose profile and substrate oxidation. It is the first study to corroborate that by constructing a 24 h low GI diet using local foods described as low GI, that these low GI Asian foods are capable of reducing $24 \mathrm{~h}$ glycaemic response and glycaemic variability and simultaneously promote fat oxidation over carbohydrate oxidation. The study expanded on previous work from our group on glycaemic index of single Asian foods on glucose response [13] and now included the measurement of substrate oxidation using a whole body calorimeter. The results are in line with the hypothesis that high GI foods result in hyperinsulinemia which in turn leads to less fat oxidation and possibly increased fat deposition $[17,37]$.

Previously, studies have shown that low GI foods can reduce the post-prandial glucose response compared to high GI foods and result in lower maximal and more stable glucose levels $[4,20,38]$. Foods classified lower in GI are more slowly digested and absorbed which result in a slower rate of appearance in the systemic circulation. This is in line with our results which show that a day of consumption of low GI mixed meals can lower $24 \mathrm{~h}$ glucose response. It is unique that this response is consistent over $24 \mathrm{~h}$ and is mediated by the consumption of commonly available low GI foods in Asia. Additionally, the results show a reduced glycaemic response after each low GI test meal with the greatest reduction occurring after breakfast, which could be explained by

Table 6 Post-prandial oxidation of carbohydrates, fat and protein in grams for subjects on a low Gl and high Gl diet $(n=9)$

\begin{tabular}{|c|c|c|c|c|c|c|}
\hline & \multicolumn{3}{|l|}{ Low Gl } & \multicolumn{3}{|l|}{ High Gl } \\
\hline & $\mathrm{CHO}(\mathrm{g})$ & Fat (g) & Protein (g) & $\mathrm{CHO}(\mathrm{g})$ & Fat (g) & Protein $(\mathrm{g})$ \\
\hline Breakfast & $27.1(2.8)$ & 6.3 (1.6) & $8.0(3.1)$ & 28.5 (3.3) & $5.3(1.8)^{*}$ & $9.3(1.1)$ \\
\hline Lunch & $50.2(6.4)$ & $11.3(2.7)$ & $13.7(5.3)$ & $56.4(4.9)^{* * *}$ & $8.1(2.1)^{* *}$ & 15.9 (1.9) \\
\hline Snack & $30.2(2.9)$ & 4.9 (1.3) & 7.4 (2.9) & $32.4(3.4)$ & 3.9 (1.6) & $8.6(1.0)$ \\
\hline Total & $107.5(8.7)$ & $22.6(4.9)$ & $29.1(11.3)$ & $117.3(9.8)^{* *}$ & $17.3(4.9)^{* *}$ & 33.8 (4.1) \\
\hline
\end{tabular}

Values are expressed as mean \pm SD; GI: glycaemic index; $\mathrm{CHO}$ : carbohydrate

${ }^{*} p<0.05,{ }^{* *} p<0.01,{ }^{* * *} p<0.001$ (paired students $t$-test) when comparing the macronutrients between the low and high Gl diet 
greater insulin sensitivity in the morning compared to later on the day [39]. There is good evidence to suggest that higher glycaemic variability can trigger more oxidative stress and it is considered a risk factor in the onset for type 2 Diabetes [23, 40]. Glycaemic variability, as assessed by mean amplitude of glycaemic excursion, showed a significantly lower variability over $24 \mathrm{~h}$ when on the low GI diet and is of specific clinical relevance for Diabetes prevention $[23,40]$. In line with and in addition to current literature, locally consumed low GI mixed meals were able to down regulate the $24 \mathrm{~h}$ glycaemic response and variability in healthy Asian subjects over the day.

An additional beneficial effects of the consumption of low GI mixed meals was the consistent higher fat oxidation compared to high GI meals. During the $10 \mathrm{~h}$ in the whole body calorimeter, fat oxidation was higher when consuming low GI meals and this result was specifically apparent after breakfast and lunch. Not surprisingly, higher carbohydrate oxidation was seen during the high GI diet. These results are in line with previous literature, as studies showed increased fat oxidation and lower blood glucose during exercise following low GI meals [41-46]. Now, the results show that in a sedentary state, the low GI mixed meals are able to improve fat oxidation while at the same time improve glycaemic response and variability. It must be noted that these results are from healthy normal weight subjects, as Diaz and colleagues were unable to reproduce the ability to modify substrate partitioning in sedentary obese subjects [47]. They concluded that the lack of effect of serum insulin on fat oxidation may be due to the short time in which insulin concentrations are maintained at higher levels following high GI versus low GI meals. Obese people might be less susceptible for increased fat oxidation and these subjects were overfed with a high GI carbohydrate load irrespective of whether the meals were low or high.

The simultaneous measurement of substrate oxidation for $10 \mathrm{~h}$ during continuous glucose monitoring provided us with a unique perspective on both glucose flux and fat tissue accretion. The results show that following low GI meals, there is a reduced glucose response and increased fat oxidation compared to high GI. Previously, several authors have reported reduced fat deposition when fed a low GI diet [37]. Our results, implicate that the reduced fat deposition during a low GI diet is driven by increased fat oxidation. It has also been shown that after a high GI meal, the higher insulin to glucagon ratio as a result of the higher increase in insulin and inhibition of glucagon, increases the uptake of carbohydrates and fat by the liver and muscles. This is in line with our results which show a lower fat oxidation after high GI mixed meals. Notably, over 10 h, low GI mixed meals resulted in an increased oxidation of $4.7 \mathrm{~g}$ of fat which translate to around $42 \mathrm{kcals}$ burned from fat, which could accumulate to around $300 \mathrm{kcals}$ per week. It must be noted that the increased energy expenditure is lower when decreased carbohydrate oxidation is taken into account. Hall et al. have shown that it may take only $7.5 \mathrm{kcal}$ extra per day to explain the current epidemic of obesity [48]. This may indicate that even in a sedentary state, a low GI diet based on locally available foods, not only lowers blood glucose but also enhances fat oxidation and may play a key role in weight regulation and maintenance.

Investigating glycaemic index and glycaemic response of locally consumed foods revealed that as expected, all high GI meals resulted fast absorption and a higher glucose response, the highest postprandial glucose response was observed after the high GI breakfast. Poon kueh is steamed glutinous rice and is commonly consumed as a breakfast amongst Asians. The mean areas under the postprandial tissue glucose curve after ingestion of the high GI breakfast was two-fold higher compared to the low GI breakfast. The high GI dinner meal, which consisted of boiled glutinous rice and side dishes, also exhibited a much higher glucose response compared to the low GI dinner. Glutinous rice has been reported for its high starch digestibility that causes sharp spikes in blood glucose responses [49].

No serum insulin measurements were available in this study which could further enhance the link between glycaemic response and fuel utilization. Protein oxidation had to be assumed to be constant as it could not be measured in a time-specific way and was based on the total $10 \mathrm{~h}$ cycle in the WBC [50]. Another limitation was the inclusion of only male subjects to avoid metabolic variability in insulin sensitivity and glycaemic response in females due to the menstrual cycle, which might bias the results due to the gender of individuals [51]. An important feature of the current study was the use of commonly consumed Asian mixed meals. Not all micronutrients and the sources of proteins and fats were possible to match and this can have an effect on glycaemic response, however percentage calories from carbohydrates, fat and protein were matched for the low and high GI diet as this is the most important in meal composition.

\section{Conclusions}

Novel findings of this study are the ability to reduce glycaemic response over $24 \mathrm{~h}$ and increase fat oxidation of a $24 \mathrm{~h}$ low GI mixed meal plan. Unique to our study was the use of Asian and commonly consumed low GI foods to construct a low GI diet and the simultaneous measurement of blood glucose (continuous glucose monitoring) and substrate oxidation using a whole body calorimeter. The improvement of glycaemic response and decrease in variability found in sedentary, normal 
weight Asians with local low GI foods are important because the Asian phenotype has been shown to be more susceptible to Diabetes compared to Caucasians $[8,9]$. Additionally in Asia, people predominantly live on a high glycaemic, high carbohydrate diet and are thus susceptible to weight gain and obesity similar to observations from animal studies [37]. Future research has to be conducted to elucidate on the link between blood glucose levels and fat oxidation shown in this study, in order to quantitate how insulin and other hormones may play a role in tissue accretion and substrate oxidation. Our observations provide public health support for the encouragement of healthier nutrition choices by consuming low GI foods.

\section{Abbreviations}

BMI: Body mass index; BMR: Basal metabolic rate; CGM: Continuous glucose monitoring; CHO: Carbohydrate; Gl: Glycaemic index; iAUC: Incremental area under the curve; MAGE: Mean amplitude of glycaemic excursion;

RQ: Respiratory quotient; WBC: Whole body calorimeter

\section{Acknowledgements}

We warmly thank the volunteers for taking the time to participate in this study.

\section{Funding}

The research was supported by the Agency for Science, Technology and Research (A*STAR), Singapore.

\section{Availability of data and materials}

The datasets generated during and/or analysed during the current study are available from the corresponding author on reasonable request.

\section{Authors' contributions}

CJK designed research, BK and RQ conducted research, BK and SGC analysed data and performed statistical analysis, CJK, BK and SGC wrote paper, CJK had primary responsibility for final content. All authors read and approved the final manuscript.

\section{Competing interests}

The authors declare that they have no competing interests.

\section{Consent for publication}

Not applicable.

\section{Ethics approval and consent to participate}

The study was conducted according to the guidelines laid down in the Declaration of Helsinki and all procedures were approved by the National Healthcare Group Domain-Specific Review Board (2014/00960). Written informed consent was obtained from all participants. This trial was registered at clinicaltrials.gov as NCT 02631083.

\section{Publisher's Note}

Springer Nature remains neutral with regard to jurisdictional claims in published maps and institutional affiliations.

\footnotetext{
Author details

${ }^{1}$ Clinical Nutrition Research Centre (CNRC), Singapore Institute for Clinical Sciences (SICS), Agency for Science, Technology and Research (A*STAR) and National University Health System, Centre for Translational Medicine, Yong Loo Lin School of Medicine, 14 Medical Drive \#07-02, MD 6 Building, Singapore 117599, Singapore. ${ }^{2}$ Department of Biochemistry, Yong Loo Lin School of Medicine, National University of Singapore, S14 Level 5, Science Drive 2 , Singapore 117543 , Singapore.
}

Received: 6 February 2017 Accepted: 24 May 2017

Published online: 12 July 2017

\section{References}

1. Jenkins DJ, Wolever TM, Taylor RH, Barker H, Fielden H, Baldwin JM, Bowling AC, Newman HC, Jenkins AL, Goff DV. Glycemic index of foods: a physiological basis for carbohydrate exchange. Am J Clin Nutr. 1981;34:362-6.

2. Foster-Powell K, Holt SHA, Brand-Miller JC. International table of glycemic index and glycemic load values: 2002. Am J Clin Nutr. 2002;76:5-56.

3. Atkinson FS, Foster-Powell K, Brand-Miller JC. International tables of glycemic index and glycemic load values: 2008. Diabetes Care. 2008;31:2281-3.

4. Brand-Miller J, Hayne S, Petocz P, Colagiuri S. Low-glycemic index diets in the management of diabetes: a meta-analysis of randomized controlled trials. Diabetes Care. 2003;26:2261-7.

5. Nansel TR, Gellar L, McGill A. Effect of varying glycemic index meals on blood glucose control assessed with continuous glucose monitoring in youth with type 1 diabetes on basal-bolus insulin regimens. Diabetes Care. 2008;31:695-7.

6. Fabricatore AN, Ebbeling CB, Wadden TA, Ludwig DS. Continuous glucose monitoring to assess the ecologic validity of dietary glycemic index and glycemic load. Am J Clin Nutr. 2011;94:1519-24.

7. Ryan RL, King BR, Anderson DG, Attia JR, Collins CE, Smart CE. Influence of and optimal insulin therapy for a low-glycemic index meal in children with type 1 diabetes receiving intensive insulin therapy. Diabetes Care. 2008;31:1485-90.

8. Venn BJ, Williams SM, Mann J. Comparison of postprandial glycaemia in Asians and Caucasians. Diabet Med. 2010;27:1205-8.

9. Haldar S, Chia SC, Henry CJ. Body Composition in Asians and Caucasians: Comparative Analyses and Influences on Cardiometabolic Outcomes. Adv Food Nutr Res. 2015;75:97-154.

10. Abdullah $A B$, Ito $S$, Adhana K. Estimate of rice consumption in Asian countries and the world towards 2050. In: Proceedings for Workshop and Conference on Rice in the World at Stake. 2006. p. 28-43.

11. Wuthi-Arporn J. Increasing Rice Production: Solution to the Global Food Crisis. 9th International Students Summit (ISS): Promoting Sustainable Agriculture to the Youth (2009). Available online: http://www.nodai.ac.jp/ cip/iss/english/9th_iss/fullpaper/1-2-2ku-jirawut.pdf. Accessed 30 May 2017.

12. Henry CJK, Lightowler HJ, Newens K, Sudha V, Radhika G, Sathya RM, Mohan $\checkmark$. Glycaemic index of common foods tested in the UK and India. Br J Nutr. 2008;99:840-5.

13. Sun L, Lee DEM, Tan WJK, Ranawana DV, Quek YCR, Goh HJ, Henry CJ. Glycaemic index and glycaemic load of selected popular foods consumed in Southeast Asia. Br J Nutr. 2015;113:843-8.

14. Lin M-HA WM-C, Lu S, Lin J. Glycemic index, glycemic load and insulinemic index of Chinese starchy foods. World J Gastroenterol. 2010;16:4973-9.

15. Chen Y-J, Sun F-H, Wong SH-S, Huang Y-J. Glycemic index and glycemic load of selected Chinese traditional foods. World J Gastroenterol. 2010;16:1512-7.

16. Yang Y-X, Wang H-W, Cui H-M, Wang Y, Yu L-D, Xiang S-X, Zhou S-Y. Glycemic index of cereals and tubers produced in China. World J Gastroenterol. 2006;12:3430.

17. Ludwig DS. The glycemic index: physiological mechanisms relating to obesity, diabetes, and cardiovascular disease. JAMA. 2002;287:2414-23.

18. Ludwig DS. Dietary glycemic index and obesity. J Nutr. 2000;130:280S-3S.

19. Brand-Miller JC, Holt SH, Pawlak DB, McMillan J. Glycemic index and obesity. Am J Clin Nutr. 2002;76:281S-5S.

20. Kaur B, Quek Yu Chin R, Camps S, Henry CJ. The impact of a low glycaemic index (Gl) diet on simultaneous measurements of blood glucose and fat oxidation: A whole body calorimetric study. J Clin Translat Endocrinol. 2016;4:45-52.

21. Baecke JA, Burema J, Frijters JE. A short questionnaire for the measurement of habitual physical activity in epidemiological studies. Am J Clin Nutr. 1982;36:936-42.

22. Van Strien T, Frijters JER, Bergers G, Defares PB. The Dutch Eating Behavior Questionnaire (DEBQ) for assessment of restrained, emotional, and external eating behavior. Int J Eat Disord. 1986;5:295-315.

23. Monnier L, Mas E, Ginet C, Michel F, Villon L, Cristol JP, Colette C. Activation of oxidative stress by acute glucose fluctuations compared with sustained chronic hyperglycemia in patients with type 2 diabetes. JAMA. 2006;295:1681-7.

24. Liu AG, Most MM, Brashear MM, Johnson WD, Cefalu WT, Greenway FL. Reducing the glycemic index or carbohydrate content of mixed meals 
reduces postprandial glycemia and insulinemia over the entire day but does not affect satiety. Diabetes Care. 2012;35:1633-7.

25. Brynes AE, Lee JL, Brighton RE, Leeds AR, Dornhorst A, Frost GS. A low glycemic diet significantly improves the $24-h$ blood glucose profile in people with type 2 diabetes, as assessed using the continuous glucose MiniMed monitor. Diabetes Care. 2003:26:548-9.

26. Brynes AE, Adamson J, Dornhorst A, Frost GS. The beneficial effect of a diet with low glycaemic index on $24 \mathrm{~h}$ glucose profiles in healthy young people as assessed by continuous glucose monitoring. Br J Nutr. 2005;93:179-82.

27. Schoffelen PF, Westerterp KR, Saris WH, Ten Hoor F. A dual-respiration chamber system with automated calibration. J Appl Physiol (1985). 1997;83:2064-72.

28. Weir JB. New methods for calculating metabolic rate with special reference to protein metabolism. J Physiol. 1949;109:1-9.

29. Wulan SN, Westerterp KR, Plasqui G. Dietary and 24-h fat oxidation in Asians and whites who differ in body composition. Am J Clin Nutr. 2012;95:1335-41.

30. Frayn KN. Calculation of substrate oxidation rates in vivo from gaseous exchange. J Appl Physiol Respir Environ Exerc Physiol. 1983;55:628-34.

31. Allison DB, Paultre F, Maggio C, Mezzitis N, Pi-Sunyer FX. The use of areas under curves in diabetes research. Diabetes Care. 1995;18:245-50.

32. Brouns F, Bjorck I, Frayn KN, Gibbs AL, Lang V, Slama G, Wolever TMS. Glycaemic index methodology. Nutr Res Rev. 2005;18:145-71.

33. Molnar GD, Rosevear JW, Ackerman E, Gatewood LC, Taylor WF. Mean amplitude of glycemic excursions, a measure of diabetic instability. Diabetes. 1970;19:644-55.

34. Guerci B. Asymptomatic glycemic instability: how to measure it and which clinical applications? Diabetes Metab. 2003;29:179-88.

35. Kovatchev BP, Clarke WL, Breton M, Brayman K, McCall A. Quantifying temporal glucose variability in diabetes via continuous glucose monitoring: mathematical methods and clinical application. Diabetes Technol Ther. 2005:7:849-62.

36. Rodbard D. Interpretation of continuous glucose monitoring data: glycemic variability and quality of glycemic control. Diabetes Technol Ther. 2009;11: S-55-S-67.

37. Pawlak DB, Kushner JA, Ludwig DS. Effects of dietary glycaemic index on adiposity, glucose homoeostasis, and plasma lipids in animals. Lancet. 2004;364:778-85.

38. Thomas DE, Elliott EJ. The use of low-glycaemic index diets in diabetes control. Br J Nutr. 2010;104:797-802.

39. Shih KC, Ho LT, Kou HF, Liu PC, Hsiao LC, Li SH, Liu YF, Wu MS. Diurnal variation of insulin sensitivity in NIDDM patients and normal subjects. J Formos Med Assoc. 1992;91:263-9.

40. Sun J, Xu Y, Sun S, Sun Y, Wang $X$. Intermittent high glucose enhances cell proliferation and VEGF expression in retinal endothelial cells: the role of mitochondrial reactive oxygen species. Mol Cell Biochem. 2010;343:27-35.

41. Stevenson $E$, Williams C, Nute M. The influence of the glycaemic index of breakfast and lunch on substrate utilisation during the postprandial periods and subsequent exercise. Br J Nutr. 2005;93:885-93.

42. Stevenson EJ, Williams C, Mash LE, Phillips B, Nute ML. Influence of highcarbohydrate mixed meals with different glycemic indexes on substrate utilization during subsequent exercise in women. Am J Clin Nutr. 2006;84:354-60.

43. Wee SL, Williams C, Gray S, Horabin J. Influence of high and low glycemic index meals on endurance running capacity. Med Sci Sports Exerc. 1999:31:393-9.

44. DeMarco HM, Sucher KP, Cisar CJ, Butterfield GE. Pre-exercise carbohydrate meals: application of glycemic index. Med Sci Sports Exerc. 1999;31:164-70.

45. Febbraio MA, Keenan J, Angus DJ, Campbell SE, Garnham AP. Preexercise carbohydrate ingestion, glucose kinetics, and muscle glycogen use: effect of the glycemic index. J Appl Physiol. (1985). 2000;89:1845-51.

46. Stevenson EJ, Thelwall PE, Thomas K, Smith F, Brand-Miller J, Trenell MI. Dietary glycemic index influences lipid oxidation but not muscle or liver glycogen oxidation during exercise. Am J Physiol Endocrinol Metab. 2009;296:E1140-1147.

47. Diaz EO, Galgani JE, Aguirre CA, Atwater IJ, Burrows R. Effect of glycemic index on whole-body substrate oxidation in obese women. Int J Obes (Lond). 2005;29:108-14.

48. Hall KD, Sacks G, Chandramohan D, Chow CC, Wang YC, Gortmaker SL, Swinburn BA. Quantification of the effect of energy imbalance on bodyweight. Lancet. 2011;378:826-37.
49. Aller EE, Abete I, Astrup A, Martinez JA, van Baak MA. Starches, sugars and obesity. Nutr. 2011:3:341-69.

50. Sato M, Nakamura K, Ogata H, Miyashita A, Nagasaka S, Omi N, Yamaguchi S, Hibi M, Umeda T, Nakaji S, Tokuyama K. Acute effect of late evening meal on diurnal variation of blood glucose and energy metabolism. Obes Res Clin Pract. 2011:5:e169-266.

51. Walsh CH, Malins JM. Menstruation and control of diabetes. Br Med J. 1977;2:177-9.

\section{Submit your next manuscript to BioMed Central and we will help you at every step:}

- We accept pre-submission inquiries

- Our selector tool helps you to find the most relevant journal

- We provide round the clock customer support

- Convenient online submission

- Thorough peer review

- Inclusion in PubMed and all major indexing services

- Maximum visibility for your research

Submit your manuscript at www.biomedcentral.com/submit 